\title{
AVALIAÇÃO DE GENÓTIPOS DE SERINGUEIRA (Hevea spp.) AO Microcyclus ulei VISANDO À IDENTIFICAÇÃO DE FONTES DE RESISTÊNCIA HORIZONTAL
}

\author{
Alderi Emidio de ARAÚJO', Antonio N. KALIL FILHO ${ }^{1}$, Márcia B. de M. NÓBREGA ${ }^{1}$
}

RESUMO - Avaliou-se, sob condições controladas, a resistência de genótipos de seringueira ao mal-das-folhas. Empregaram-se dois isolados de Microcyclus ulei, pertencentes aos grupos I e II. Utilizaram-se mudas em sacos plásticos e inocularam-se folíolos nos estádios B1/B2 com uma suspensão de $2 \times 10^{5}$ conídios $/ \mathrm{ml}$. Incubaram-se as mudas em câmara úmida a $24^{\circ} \mathrm{C}$ por 24 horas. Determinaram-se o periodo latente (PL), diâmetro das lesões (DL), tipo de lesão (TL) e tipo de reação (TR). A maioria dos genótipos testados foi suscetível a pelo menos um isolado do patógeno. Os genótipos que apresentaram resistência moderada, com maior período latente e menor esporulação a um isolado, em geral, foram suscetiveis ao outro. Apenas o genótipo AM/86/271 exibiu resistência incompleta, caracterizada por maior PL, menor DL e baixa esporulação. Entretanto, o número de isolados testados não assegurou o caráter da resistência. Com base nos resultados obtidos concluiu-se que os genótipos avaliados não apresentaram perspectivas para utilização em programas de melhoramento visando resistência ao M.ulei.

Palavras chaves: Microcyclus ulei, Seringueira, Hevea, Resistência

Assessment of Hevea Rubber tree Genotypes ( Hevea spp.) to Microcyclus Ulei to Identify Sources of Horizontal Resistance.

ABSTRACT - The resistance of Hevea rubber tree genotypes to south american leaf blight was evaluated. Two isolates of Microcyclus ulei included in the stage I and II were used. Seedlings in polyetilene bags were inoculated in the B1/B2 growth state with $2 \times 10^{5}$ conidia $/ \mathrm{ml}$. The plants were incubed in humid chamber for 24 hours at $24^{\circ} \mathrm{C}$. The latent period (PL), lesion diameter (DL), lesion type (TL), and the reaction type (TR) were determined. The major of genotypes were complete susceptible to at least one isolated of the pathogen. The genotypes that showed moderate resistance to one isolate, generally were suscetible to the other. Only the AM/86/271 genotype showed incomplete resistance characterized by larger PL, small DL and low sporulation, although the number of isolates tested do not warrant the resistance type. Based in these results we concluded that the genotypes tested do not have perspectives to be used in a breeding program for resistance to M.ulei.

Key words: Microcyclus ulei, Rubber tree, Hevea, Resistance

\section{INTRODUÇÃO}

O mal-das-folhas, causado por Microcyclus ulei (P. Henn.) v. Arx, constitui-se na mais importante doença da seringueira na América Latina. No Brasil, encontra-se presente em todas as regiões onde se cultiva a seringueira, causando danos sinificativos à produção, especialmente nas regiões norte e sudeste da Bahia e em alguns municípios do estado do Mato Grosso (GASPAROTTO et al., 1990, JUNQUEIRA et al, 1988). Desde os primeiros surtos do mal-das-folhas no Brasil, vêm sendo feitas tentativas de obtenção de clones com alta produtividade e resistentes ao $M$. ulei (LANGFORD, 1945). No entanto, os resultados não têm sido satisfatórios.

EMBRAPA, Centro de Pesquisa Agroflorestal da Amazônia Ocidental, Caixa Postal 319, 69.011-970, Manaus - AM 
Em geral, os hibridos obtidos a partir das primeiras pesquisas com melhoramento genético visando resistência ao $M$. ulei em Fordlândia e Belterra (PAIVA \& GONÇALVES, 1989), apresentavam resistência vertical (HASHIM \& PEREIRA, 1989). Ao longo dos anos, os clones descritos como resistentes, tiveram sua resistência quebrada em curto espaço de tempo, pelo aparecimento de novos patótipos do patógeno (KALIL FILHO \& JUNQUEIRA, 1989; LANGDON, 1965; MILLER, 1966; CHEE et al., 1986).

A alta suscetibilidade de $H$. brasiliensis, motivou o emprego de outras espécies de Hevea no programa de melhoramento genético. Assim, a base da resistência ao $M$. ulei passou a ser constituída de híbridos de $H$. benthamiana com H. brasiliensis (VALOIS, 1978; PAIVA \& GONÇALVES, 1989; KALIL FILHO \& JUNQUEIRA, 1989). Mais recentemente, foram realizados estudos visando determinar a variabilidade fisiológica do $M$. ulei e caracterizar o germoplasma de seringueira, com o objetivo de conhecer o caráter da resistência ao patógeno e direcionar os esforços para a obtenção de clones com resistência horizontal (JUNQUEIRA, 1985; JUNQUEIRA et al., 1986).

O objetivo deste trabalho foi avaliar genótipos produzidos pelo programa de melhoramento genético de seringueira do Centro de Pesquisa Agroflorestal da Amazônia Ocidental quanto à resistência a isolados de $M$. ulei visando à obtenção de materiais com resistência horizontal.

\section{MATERIAL E MÉTODOS}

Empregaram-se dois isolados de M. ulei pertencentes aos grupos de patogenicidade I e II (JUNQUEIRA, 1985), obtidos em jardim clonal localizado na área do Centro de Pesquisa Agroflorestal da Amazônia Ocidental da EMBRAPA, em Manaus$\mathrm{AM}$, os quais foram previamente caracterizados através da inoculação em clones diferenciadores e, posteriormente, cultivados em meio de batata-sacarose-Ágar (BSA) enriquecido com um complexo vitamínico comercial de nome "Panvit" (JUNQUEIRA et al., 1986). Após o cultivo, inocularam-se mudas dos clones diferenciadores IAN 717 e Fx 4098 e mantiveram-se "in vivo" em câmara de crescimento a $24 \pm 1{ }^{\circ} \mathrm{C}$ e $85 \%$ de U.R. nestes clones por meio de inoculações sucessivas. Testaramse 22 genótipos oriundos do cruzamento entre os clones Fx 4098 e IAN 6158. Inoculou-se uma suspensão de $2 \times 10^{5}$ conídios/ $\mathrm{ml}$ na superfície abaxial de foliolos nos estádios B1/B2 (HALLÉ et al., 1978), utilizando-se um pequeno pulverizador modelo Paashe air brush H3, Chicago USA (JUNQUEIRA et al.., 1988). Inocularam-se duas plantas por genótipo e seis folíolos por planta. Após a inoculação, as plantas foram mantidas em câmara úmida por $24 \mathrm{~h}$ a $95 \%$ de U.R. e temperatura de $24 \pm 1{ }^{\circ} \mathrm{C}$ e transferidas posteriormente para câmaras de crescimento à mesma temperatura $\mathrm{e}$ $85 \%$ de U.R. até o término das avaliações, aos 15 dias após a inoculação. As avaliações foram feitas medindo-se o período latente e determinando-se o diâmetro das lesões, tipo de lesão e tipo de reação, empregando-se a escala proposta por JUNQUEIRA et al., (1988) e descrita a seguir: 
0 -Lesões cloróticas com diâmetro inferior a 1 $\mathrm{mm}$ sem esporos

1 -Lesões necróticas com diâmetro inferior a $1 \mathrm{~mm}$ sem esporos

2 -Lesões necróticas com diâmetro de 1 a 2 $\mathrm{mm}$ sem esporos

$3 \mathrm{~A}$-Lesões necróticas com diâmetro superior a $2 \mathrm{~mm}$ sem esporos

3B -Lesões nào necróticas sem esporos

4A - Lesôes com diâmetro até $2 \mathrm{~mm}$ e esporulaçào apenas nas bordas

4B -Lesões com diâmetro superior a $2 \mathrm{~mm}$ e esporulação apenas nas bordas

$5 \mathrm{~A}$ - Lesões com diâmetro até $2 \mathrm{~mm}$ e esporulação parcial em toda a superfície

5B - Lesões com diâmetro superior a $2 \mathrm{~mm}$ e esporulação parcial em toda a superfície

6 - Lesões com diâmetro até $1,5 \mathrm{~mm}$ e abundante esporulaçào na face abaxial

7 - Lesões com diâmetro entre 1,5 a $2,5 \mathrm{~mm} \mathrm{e}$ abundante esporulação na face abaxial

8 - Lesǒes com diâmetro entre 1,5 a $2,5 \mathrm{~mm}$, esporulaçào na face adaxial e abundante esporulação na face abaxial

9 - Lesões com diâmetro superior a $2,5 \mathrm{~mm}$ e abundante esporulação na face abaxial

10 - Lesões com diâmetro superior a $2,5 \mathrm{~mm}$, esporulação na face adaxial e abundante esporulação na face abaxial. dependentes do isolado. Portanto, para $o$ isolado do grupo I, os parentais foram classificados como Altamente Resistente (Fx 4098) e Moderadamente Resistente (IAN 6158). Para o isolado do grupo II foram considerados Altamente Suscetivel ( $\mathrm{Fx}$ 4098) e Moderadamente Resistente (IAN 6158) (Tab. 1). A maioria dos genótipos testados apresentou resistência ou suscetibilidade a pelo menos um isolado. O genótipo AM/86/ 271 apresentou resistência moderada aos dois isolados, em função do maior período latente e menor esporulação (Tab. 2). Os genótipos AM/86/29 e $\mathrm{AM} / 86 / 108$, apresentaram o maior periodo latente ao isolado do grupo II, sendo o primeiro resistente ao isolado do grupo I. O genótipo 20/340/82, apresentou resistência moderada ao isolado do grupo I, com período latente de 9 dias, mas foi altamente suscetivel ao isolado do grupo II, ao

Tabela 1. Reação dos parentais dos genótipos avaliados quanto à resistencia ao Microcyclus ulei

\begin{tabular}{|c|c|c|c|c|c|c|c|}
\hline \multirow[t]{3}{*}{ parentais } & \multirow[t]{3}{*}{ ancestralidade } & \multicolumn{6}{|c|}{ isolados } \\
\hline & & \multicolumn{3}{|c|}{ grupo I } & \multicolumn{3}{|c|}{ grupo II } \\
\hline & & $P L^{1}$ & $\mathrm{DL}^{2} \quad \mathrm{TL}^{3}$ & $\mathrm{TR}^{4}$ & PL & DL $\quad T L$ & TR \\
\hline Fx 4098 & PB $86 \times$ FB 74 & * & $0,5 \quad 1$ & AR & 5 & $2,5 \quad 8$ & AS \\
\hline IAN 6158 & F516 (F4542 XAVROS 363 ) X PB 86 & 8 & $1,5 \quad 4 \mathrm{~A}$ & MR & 9 & $1,5 \quad 5 \mathrm{~A}$ & MR \\
\hline
\end{tabular}

1: período latente (dias); 2: diâmetro da lesăo $(\mathrm{mm}) ; 3$ : tipo de lesão; 4 : tipo de reaçäo: * năo esporulou

Com base nas notas obtidas, os genótipos foram enquadrados nas cinco classes a seguir:0 - 1: Altamente resistente (AR), 2 - 3: Resistente (R), 4 - 5: Moderadamente Resistente (MR), 6 - 7: Suscetível (S), 8 -10: Altamente Suscetível (AS).

\section{RESULTADOS E DISCUSSÃO}

As reações nos parentais foram passo que $A M / 86 / 415$ apresentou resistência moderada ao isolado do grupo II, porém com periodo latente semelhante ao de genótipos que apresentaram alta suscetibilidade $e$, ao mesmo tempo, foi suscetivel ao isolado do grupo I.

O pouco conhecimento disponivel sobre o caráter da resistência da seringueira ao M. ulei, tem limitado os 
Tabela 2. Reação de genótipos de seringueira (Heveu spp) quanto a resistência ao Microcyclus ulei

\begin{tabular}{|c|c|c|c|c|c|c|c|c|}
\hline \multirow{3}{*}{ genótipos } & \multicolumn{8}{|c|}{ isolados } \\
\hline & \multicolumn{4}{|c|}{ Grupo 1} & \multicolumn{4}{|c|}{ Grupo II } \\
\hline & $P L^{1}$ & $\mathrm{DL}^{2}$ & $\mathrm{TL}^{3}$ & $\mathrm{TR}^{4}$ & $P L$ & $\mathrm{DL}$ & $T L$ & TR \\
\hline $\mathrm{AM} / 86 / 14$ & 6,0 & 3,0 & 8 & AS & 6,0 & 2,0 & 8 & AS \\
\hline $\mathrm{AM} / 86 / 18$ & 5,0 & 3,0 & 10 & AS & 6,0 & 2,5 & 7 & $S$ \\
\hline $\mathrm{AM} / 86 / 29$ & * & 1,0 & 2 & $\mathrm{R}$ & 10,0 & 1,5 & $4 \mathrm{~A}$ & MR \\
\hline $20 / 340 / 82$ & 9,0 & 1,5 & $5 \mathrm{~A}$ & MR & 5,0 & 3,2 & 8 & AS \\
\hline AM/86/106 & 5,0 & 2,5 & 8 & AS & 5,5 & 3,0 & 8 & AS \\
\hline AM/86/108 & $* *$ & $* *$ & $* *$ & $\star *$ & 10,0 & 1,0 & $4 \mathrm{~A}$ & MR \\
\hline $\mathrm{AM} / 86 / 116$ & * & 1,0 & 2 & $R$ & * & 1,0 & 2 & $\mathrm{R}$ \\
\hline AM/86/117 & 6,0 & 2,0 & 7 & $S$ & 5,0 & 1,5 & 7 & $S$ \\
\hline AM/86/126 & * & 1,0 & 2 & $R$ & 5,0 & 2,5 & 8 & AS \\
\hline $\mathrm{AM} / 86 / 150$ & 6,0 & 2,8 & 10 & AS & 6,0 & 2,6 & 8 & AS \\
\hline $\mathrm{AM} / 86 / 224$ & * & 1,0 & 2 & $R$ & * & 1,0 & 2 & $\mathrm{R}$ \\
\hline $\mathrm{AM} / 86 / 229$ & * & 1,0 & 2 & $R$ & * & 1,0 & 2 & $\mathrm{R}$ \\
\hline AM/86/148 & * & 0,8 & 1 & AR & * & 1,0 & 2 & R \\
\hline AM/86/315 & 6,0 & 2,0 & 7 & S & 5,0 & 3,5 & 10 & AS \\
\hline AM/86/318 & * & 1,0 & 2 & $\mathrm{R}$ & * & 1,5 & $3 B$ & $R$ \\
\hline AM/86/271 & 7,0 & 1,5 & $5 \mathrm{~A}$ & MR & 8,0 & 1,5 & $4 \mathrm{~A}$ & MR \\
\hline AM/86/354 & 6,0 & 2,0 & 8 & AS & 5,0 & 3,3 & 8 & AS \\
\hline AM/86/415 & 7,0 & 2,0 & 7 & $s$ & 6,2 & 1,5 & $5 \mathrm{~A}$ & MR \\
\hline AM/86/433 & 6,0 & 2,3 & 7 & S & 6,5 & 2,0 & 7 & S \\
\hline AM/86/984 & * & 1,0 & 2 & $\mathrm{R}$ & * & 1,0 & 2 & $R$ \\
\hline AM/86/1062 & * & 1,0 & 2 & R & * & 1,0 & 2 & $R$ \\
\hline $\mathrm{AM} / 86 / 37$ & ${ }^{*}$ & 1,0 & 2 & $\mathrm{R}$ & 5,5 & 2,0 & 8 & AS \\
\hline
\end{tabular}

* não esporulou; ** não testado; 1: periodo latente (dias); 2 : diâmetro da lesão (mm); 3 : tipo de lesão; 4: tipo dereação.

esforços para obtenção de materiais genéticos resistentes. A maioria dos clones comerciais empregados na Amazônia, são híbridos entre $H$. brasiliensis $\times H$. benthamiana e o clone $\mathrm{F} 4542(H$. benthamiana), que apresenta resistência vertical (JUNQUEIRA, 1985), constituiu-se na principal fonte de resistência utilizada nos cruzamentos que originaram estes híbridos (KALIL FILHO \& JUNQUEIRA, 1989). O clone IAN 6158, um dos parentais dos genótipos avaliados no presente trabalho, é descendente do F 4542 (Tab.1); apresentava-se promissor como fonte de resistência horizontal ao $M$. ulei. Entretanto, GASPAROTTO et al., (1992) identificaram um surto do maldas-folhas em área enxertada de copa com este clone no estado do Amazonas. Este fato pode estar relacionado à possível quebra de resistência por um patótipo mais virulento do patógeno, o que demonstra sua ineficácia como fonte de resistência durável ao $M$. ulei. No presente estudo, constatou-se suscetibilidade na maioria dos genótipos a ambos os isolados. Apesar 
do genótipo AM/86/271 ter apresentado resistência incompleta, não é possível assegurar o caráter dessa resistência, especialmente em função do reduzido número de isolados testados. Ensaios posteriores, empregando-se maior número de isolados, poderiam indicar com maior precisão o caráter da resistência deste genótipo.

A análise da resistência/ suscetibilidade da descendência do cruzamento Fx 4098 x IAN 6158, mostra a existência de alguns indivíduos resistentes e outros suscetíveis aos isolados dos dois grupos de patogenicidade de $M$. ulei. Portanto, a ocorrência de segregação evidencia a heterozigozidade para resistência no clone Fx 4098.

Ao considerar o comportamento do parental Fx 4098, que apresenta alta suscetibilidade ao isolado do grupo II e resistência completa ao isolado do grupo I, bem como a suscetibilidade expressa pelo IAN 6158 (GASPAROTTO et. al., 1992), concluiu-se que os genótipos testados no presente trabalho, não apresentaram perspectivas de êxito em programas de melhoramento visando resistência horizontal ao M. ulei.

\section{Bibliografia citada}

CHEE, K. H. ; DARMONO, T. W.; SANTOS, A. F. 1986. Laboratory screening of fungicides using cellulose film and leaf discs against south american leaf blight pathogen, Microcyclus ulei. J. Nat. Rubb. Res. 1 (2): 98-103

CHEE, K. H.; WASTIE, R. L. 1980. The status and future prospects of rubber diseases in tropical America. Rev. Plant.
Pathol. 54 (12): 541-7

GASPAROTTO, L; ARAUJO, A. E.; LIMA, M. I. P. M.; SANTOS, A. F. 1992. Surto do mal-das folhas (Microcyclus ulei)em seringal enxertado com copa do clone IAN $6158 \mathrm{em}$ Manaus-AM. Fitopatol. bras. $17(2$ ), p. 192, (resumo)

GASPAROTTO, L.; FERREIRA, F. A.; LIMA, M. I. P. M. ; PEREIRA, J. C. R. SANTOS, A. F. 1990. Enfermidades da Seringueira no Brasil. Manaus: EMBRAPA-CPAA, 169 p. (EMBRAPACPAA, Circular Técnica, 3).

HALLÉ, F.; OLDEMAN, R, A A.; TOMLINSON, P. B. 1978. Tropical trees and forest. Berlin, Springer-verlag, $441 \mathrm{p}$.

HASHIM, I. ; PEREIRA, J, C. R. 1989. Lesion size, latent period and sporulation on leaf discs as indicators of resistance of Hevea to Microcyclus ulei.J. Nat. Rubb. Res., 4: 56-60.

JUNQUEIRA, N. T. V. 1985. Variabilidade Fisiológica de Microcyclus ulei (P. Henn.) v. Arx. Viçosa, UFV. 135 p. Tese Doutorado.

JUNQUEIRA, N. T. V.; CHAVES, G. M.; ZAMBOLIN, L.; ALFENAS, A. C. GASPAROTTO, L. 1988. Reação de clones de seringueira a vários isolados de Microcyclus ulei. Pesq. Agropec. Bras. 23 (8): 877-93.

JUNQUEIRA, N. T. V.; CHEVES, G. M.; ZAMBOLIN, L.; GASPAROTTO, L.; ALFENAS, A. C. 1986. Variabilidade fisiológica de Microcyclus ulei . Fitopatol. bras. 11 (4): 823-34

KALIL FILHO, A. N.; JUNQUEIRA, N. T. V. 1989. Bases e procedimentos para o programa de melhoramento de seringueira no CNPSD-Manaus, AM. Manaus, EMBRAPA-CNPSD, 13 p. (EMBRAPA-CNPSD. Documentos, 8).

LANGDON, K. R. 1965. Relative resistance or susceptibility of several clones of Hevea brasiliensis and $H$. brasiliensis $\mathrm{x}$ $H$. benthamiana to two races of Dothidela ulei. Plant. Dis. Rept. 49 (1): 12-4.

LANGFORD, M. H. 1945, South American leaf blight of Hevea rubber trees Tech Bull. Us. Dep. Agric. 882, 31 p. 
MILLER, J. W. 1966. Diferencial clones of Hevea for identifying races of Dothidela ulei. Plant, Dis. Rept, 30: 187-90.

PAIVA, J. R.; GONÇALVES, P. S. 1989. Eficiência do programa de melhoramento da seringueira no Centro Nacional de Pesquisa de Seringueira e Dendé-nove anos de experiências. Manaus, EMBRAPA-CNPSD, 41. p. (EMBRAPA-CNPSD, Boletim de Pesquisa 2).
VALOIS, A. C. C. 1978. Melhoramento genético de seringueira. In: EMPRESA BRASILEIRA DE PESQUISA AGROPECUÁRIA. Curso de Especialização em heveiculura, Belém, 24p. 